\title{
BUSINESS PERFORMANCE IN THE POST-STARTUP PHASE: THE CASE OF LATAM FOR-PROFIT VENTURES PARTICIPATING IN ACCELERATOR PROGRAMS
}

\author{
DESEMPEÑO EMPRESARIAL EN LA FASE POSTERIOR A LA PUESTA EN MARCHA: EL \\ CASO DE EMPRESAS CON FINES DE LUCRO PARTICIPANTES EN PROGRAMAS DE \\ ACELERACIÓN EN LATINOAMÉRICA
}

\author{
Carlos Eduardo Canfield Rivera ${ }^{\mathrm{a}}$ \\ Classification: Empirical paper - research \\ Received: June 6, 2020 / Revised: September 21, 2020 / Accepted: October 10, 2020
}

\begin{abstract}
This study aims at a more systematic understanding of the critical factors, based on Sharir \& Lerner's (2006) framework, that exert influence over the probabilities of performance development of For-Profit Ventures participating in accelerator programs worldwide, and specifically in the LATAM Region. Using an Ordinal Logit Regression Model on secondary data from a multipurpose survey over a sample of startups in more than 170 countries, the positive effects of such factors were first tested, and differential behaviour was sought, in ventures operating in the LATAM Region. Even though most of the factors accounted for in the framework were validated in the general sample and their effects were quantified, differential behaviour due to socio-economic and geographic conditions was found in the region; the most striking result revolved around the statistically confirmed notion that LATAM ventures have learned to operate in underprivileged conditions. Conclusions are drawn in support of harmonized for-profit entrepreneurship promotional programs and the adoption of standardized impact measurement criteria in order to improve the access to outside-funds. This argument raises ample academic and practical possibilities for investigating the impact of socio-economic and cultural influences on the efficacy of entrepreneurial support mechanisms. This study contributes to the literature by providing more empirical research about performance development in newly created for-profit ventures and the effectiveness of global accelerator programs.
\end{abstract}

Keywords: For-profit ventures, success factors, international comparative study, global accelerator learning initiative, ordinal logistic regression

\section{Resumen}

El estudio busca una comprensión más sistemática de los factores, con el marco de Sharir y Lerner (2006), que ejercen influencia sobre las probabilidades de desarrollo del desempeño de las empresas lucrativas que participan en programas de aceleración en todo el mundo, con énfasis en Latinoamérica, contribuyendo a la investigación empírica sobre el tema. Utilizando un modelo de regresión logística ordinal en los datos de una encuesta multipropósitos sobre una muestra de startups en más de 170 países, se probaron por primera vez los efectos positivos de dichos factores, y se buscó un comportamiento diferencial, en empresas que operan en Latinoamérica. A pesar de que la mayoría de los factores considerados en el marco de referencia se cuantificaron y validaron en la muestra general, se encontró un comportamiento diferencial debido a las condiciones socioeconómicas y geográficas en la región; el resultado

a Universidad Anáhuac, Huixquilucan, México. Email: Carlos.canfield@anahuac.mx 
más llamativo giró en torno a la noción estadísticamente confirmada de que los empresarios en Latinoamérica han aprendido a operar en condiciones desfavorables. Los resultados del estudio apoyan el establecimiento de programas armonizados de promoción del emprendimiento lucrativo y la adopción de criterios estandarizados de medición de impacto para mejorar el acceso a fondos externos. Este argumento plantea amplias posibilidades académicas y prácticas para investigar el impacto de las influencias socioeconómicas y culturales en la eficacia de los mecanismos de apoyo empresarial y contribuye a la literatura proporcionando mayor investigación empírica sobre el desarrollo del rendimiento en empresas lucrativas de nueva creación y la eficacia de los programas de aceleración globales.

Palabras clave: empresas lucrativas, factores de éxito, estudio comparativo internacional, Global Accelerator Learning Initiative, regresión ordinal logística

\section{Introduction}

Many studies dating from the 1980's to the present, have established that entrepreneurial activity, measured in terms of size and age, is positively related to economic growth (Baumol \& Strom, 2007; Carree \& Thurik, 2010; Thurik \& Wennekers, 2004); some authors deem entrepreneurial activity as productive and worthy of encouragement (Acs et al., 2009; Acs \& Stough, 2008; Morris et al., 2013); moreover several researchers believe that new ventures contribute to increasing levels of competition, create value for customers, generate employment and tax revenue and in general play an important role in society (Birch, 1979; Reynolds, 1987; Storey, 1994; Thurik \& Wennekers, 2004). With this potential in mind, the surge of a cluster of public policies that encourage entrepreneurship and seek to support new businesses (NVs), such as incubators, accelerators, technology parks, among other initiatives, is not surprising.

Nevertheless, the direct positive effect of NVs over economic growth has not been proven; under a different venue, certain studies also account for differential results regarding the distribution of benefits stemming from entrepreneurial and new businesses activities. Authors such as Van Stel et al. (2005) and Hall \& Sobel (2008), argue that depending on the region's general stage of development, and on the quality of their institutional arrangements, entrepreneurial activity by both nascent entrepreneurs and NV managers has a differential geographic effect on economic growth, raising concerns around the notion that alone, the direct economic potential of nascent ventures may possibly be over-emphasized (Alvarez \& Barney, 2014). On the one hand, Reynolds (1987) showed that NVs generated between $60-80 \%$ of jobs, sales and exports in the United States, but on the other hand, after further research, a strong argument is built around the true economic effect of entrepreneurship that leads to different perspectives and possible alternative conclusions. It has been established that the positive effect of entrepreneurial activity over job creation is strongly related to fast growing firms, as opposed to the contribution of small and medium enterprises (SME's) in advanced countries (Alvarez \& Barney, 2014; Wong et al., 2005) ); as per the case of this study, these last findings can also be observed in other economies, where competitive conditions have been found to determine the entrepreneurial trajectory of new businesses, as is the case for Latin-American new ventures (Acs \& Amorós, 2008). Historically, given the early contributions of Schumpeter (1934), the conceptualization of disruptive entrepreneurs as innovators, has prevailed in the literature (Hagedoorn, 1996). Extant literature, mostly descriptive, considers that entrepreneurial innovation generates economic potential (Lumpkin \& Dess, 1996; Miller \& Friesen, 1982; Vesper, 1980), despite the intrinsic difficulty to empirically test this assertion (Wong et al., 2005); consequently an argument favouring the notion that entrepreneurial innovation creates disruption and competition while enhancing rivalry, and in that sense, the fact that it is one of the main driver's in today's global economic growth is not undisputed.

Following those lines to the extreme, in his article, Shane (2009) argued that the typical start-up, remains small, is not innovative, creates few jobs, and generates little wealth. He also argued that designing public policies which encourage more people to become entrepreneurs is counterproductive, therefore policy makers should stop subsidizing the formation of the typical start-up and focus on the subset of businesses with growth potential, such as the so-called unicorns or gazelles. Authors such as Morris et al. (2015) state that Shane's position is representative of the dominant perspective in entrepreneurship (Delmar et al., 2003; Stangler, 2010) and counter-argue in favour of a portfolio perspective on entrepreneurship, considering four types of start-up ventures: survival, lifestyle, managed growth and aggressive/high growth, with each having differing needs, to be addressed possibly by public policy, and making unique and positive contributions to the economic welfare of a nation, region, or locality (Morris et al., 2018). 
With respect to the systematic study of entrepreneurship, more specifically its economic importance and the elements of public policy required to harness such potential, a strong bias towards considering successful, technology-based companies as paradigmatic in the study of entrepreneurial activity has been frequently accounted for in the current literature (Lehmann \& Schenkenhofer, 2019). Aldrich and Ruef (2018, p. 458) believe that despite the attention given by scholars and policy-makers to the so-called "unicorn and gazelle" firms in many journals and entrepreneurship conferences, the actual occurrence of IPO's and Venture Capital Funding events for these enterprises is quite scarce; thereby these authors argue that entrepreneurship scholars have been paying a disproportionate share of attention to these unusual startups; for that matter, correcting the misperception that has been introduced through selection biases favouring growing and profitable firms will give scholars and policymakers a more accurate and policy-relevant picture of entrepreneurship in the 21 st century. Moreover, understanding the diversity of nascent ventures, particularly under the portfolio approach as proposed by Morris et al. (2015) could provide an ample set of guidelines for policy-makers in order to develop a proper framework for entrepreneurial development in various geographic and business settings.

What has been well accounted for, both in practice and in the literature, is that startups usually face difficult operational conditions that subordinate their survival in the early stages. The failure and low-growth risks of NVs are high; several studies show that the mortality rate of new businesses is at least $30 \%$ in the first two years of operation (Headd, 2003); a study by Van de Ven et al. (1984) concluded that $54 \%$ of businesses survive a year and a half after their inception, and only $25 \%$ survive by the sixth year. Phillips and Kirchhoff (1989), using data from Dun \& Bradstreet, found that $76 \%$ of new companies were still in operation after two years, $47 \%$ after four years, and $38 \%$ after six years. These figures are consistent with other studies (Audretsch et al., 1999; Bartelsman et al., 2005); nevertheless, it has also been shown that mortality rates are heterogeneous across all industries, and the service sector is the one that reflects highest deaths, followed by retail and technological companies.

With various degrees of success, some mechanisms including venture capitalists (VCs), accelerators, incubators, science parks, angel funders (AFs), co-working environments, educational programs, matching platforms, and pair-up events have been devised to support the creation, development and funding of a small sub-set of nascent enterprises, particularly those that exhibit some potential, in an attempt to mitigate these well-known failure rates (Wise \& Valliere, 2014). In the early stages, these institutions help promising NVs in defining and building their products; identifying their business model; recognizing potential market opportunities and attaining access to business resources such as capital, innovative technologies, employees and potential customers (Cohen, 2013).

Accelerators are fixed-term, cohort-based programs formed by groups of experienced businesspeople, offering a combination of small capital seeds (networking and management services, shared office space, education and expertise to NVs) on an as-needed basis to help them succeed in their early stages; they address both, the funding and the information gaps for startups and would-be investors by acting as network brokers, reducing the search costs for AFs and VCs, while creating a pipeline of vetted technologies for the market (Cohen \& Hochberg, 2014; Fishback et al., 2007).

After Y Combinator in 2005, the popularity of accelerators has been boosted by famous participants like Dropbox, Reddit, and Airbnb, contributing to the notion of what is known today in the literature as the Silicon Valley mania (Aldrich \& Ruef, 2018; Lehmann \& Schenkenhofer, 2019; Morris et al., 2018; Walker, 2018). Nevertheless; despite abundant realization stories and presumed benefits of accelerators, their advocates face criticism, not only for these mechanisms' lack of depth and breadth in supporting nascent ventures, but also for the deficiency of statistical data and metrics to validate this impression. Notwithstanding accelerator programs abound worldwide, little is known about their effectiveness. Cohen (2013) claims that the efficacy of these programs is not clear, arguing that given the heterogeneity between programs, it's likely that accelerator outcomes are themselves heterogeneous; moreover, Dempwolf et al. (2014) disputed that the lack of an accelerator's unified definition resides in the wide array of acceleration models and funding sources emerging around the world.

Few publications study the effects that accelerators are having on the ability of selected NVs to grow revenues, create employment, and attract outside investment (Gonzalez-Uribe \& Leatherbee, 2017; Hallen et al., 2014; Radojevich-Kelley \& Hoffman, 2012; Winston-Smith \& Hannigan, 2015); to address the information shortcoming of accelerator's activities, the Social Enterprise @ Goizueta at Emory University and the Aspen Network of Development Entrepreneurs (ANDE), in collaboration with a consortium of public and private funders, launched the Global Accelerator Learning Initiative (GALI), which builds on the work of the Entrepreneurship Database Program at Emory (EDP). This program collects data from individual ventures in more than 170 countries 
during their application process at contributing accelerators; after six months they resurveyed entrepreneurs, whether they were accepted or not in the accelerator programs, gathering follow-up data (GALI, 2018).

What Factors Affect Post-Startup Success in ForProfit Ventures Applying to Accelerator Programs?

Since start-up attempts are not always successful, and in the venue of appraising their performance in the poststartup phases, this research attempts to attain further methodical knowledge of factors known to either exert influence over economic performance or, moreover, contribute to the success of for-profit ventures (FPVs) that participate in entrepreneurial support mechanisms, such as accelerators. Using an Ordinal Logistic Regression (OLR) model estimated over a unique and ample dataset provided by the EDP, the first-hand objective of our study is to provide a more systematic understanding of the factors believed to be conducive of success, in FPVs applying to 283 accelerator programs around the world; further-on, based on additional empirical analysis, this research attempts to find differential performance determinants originated by the specific socio-economic and geographic divergences of the factors affecting the probability of success in an EDP's sub-sample of FPVs, in both Latin American and Caribbean (LATAM) countries - as per the World Bank Classification - and the rest of the world.

\section{Critical Success Factors: The Key to New Ventures} Performance

Literature reports that Critical Success Factors (CSFs) account for the majority of the determinants for a successful enterprise in general (Boynton \& Zmud, 1984) and specifically for small and medium enterprises as well (Al-Tit et al., 2019). Rockart (1979) defined CSFs as the limited number of areas in which satisfactory results will ensure successful competitive performance for the organization; whereas other authors such as Lynch (2003) and Bruno et al. (1987), describe them as the resources, skills, and attributes of an enterprise that are essential for success.

As per this quest, NVs being studied (either for-profit or socially oriented) have applied and/or participated in accelerator programs affiliated with more than 90 programs worldwide; these programs share a common interest in selecting ventures with Impact Investment potential. Following Canfield and Anzola's (2018) study about factors conducive to success in socially oriented ventures (SOVs), given the social motivation bias present in the sample being studied, in this research, the success factors initially considered derive from the study of social organizations by Sharir and Lerner (2006); their research is grounded on the conceptual framework for describing new venture creation proposed by Gartner (1985) and complemented by Cooper (1993) and Duchesneau and Gartner (1990). This framework integrates four major perspectives in entrepreneurship: characteristics of the individuals who start the venture, the organization which they create, the environment surrounding the new venture, and the process by which the new venture is started. The Sharir and Lerner's factors are successively adapted to the specific conditions of data collected in the EDP's sample in 2013-2018. Besides, considering both, the nature and limitations of the database used in this analysis, attention is given to the relative importance of other approaches and variables that stemmed from Gartner's (1985) framework of new venture creation as per the exploratory study of nascent entrepreneurs in Gelderen et al. (2005). Our research poses two main questions: What are the general factors affecting the probability of success of FPVs that participated in accelerator programs in our sample in 2013-2018? And, if a differential success behaviour, regarding those factors, exists in companies operating in the LATAM Region? The OLR model employed in this approach estimates the effects of considered critical factors over the probability of enhancing the performance of FPVs.

The remaining sections of the study are structured as follows: In the second section, the relevant literature that supports the conceptual framework as well as the hypotheses under study are established; in the third section, materials and methods are discussed, followed by estimation results and their discussion. The hypotheses of the study are then validated and practical and academic implications of the study and directions for further research are lastly addressed.

\section{Literature Review and Hypotheses Statement}

Despite the fact that the economic importance of NVs needs to be re-evaluated and a more accurate and policyrelevant picture of entrepreneurship in the 21 st century is required (Aldrich \& Ruef, 2018), the study recognizes that a wide array of government and private sector-sponsored mechanisms, among them accelerators, have been established to support business development and improve survival rates, given the high failure rate of small businesses (SBs) and specifically startups; thereby following Zinger et al.'s (2001) research into the factors perceived to influence the performance of emerging SBs is of utmost importance for the proper orientation of public policy regarding this matter. 
It has been argued that a founder's performance is determined not only by personal talent, circumstances and good luck, but also by his/her human, social, and financial capital (Bosma et al., 2004); initially NVs' financing is accomplished with their own resources or through the help of friends and family; entrepreneurship is a matter of recognizing and taking advantages of opportunities and transforming them into economic value (Helfat \& Lieberman, 2002), yet most founders do not have the capital, material, or expertise to fully exploit the entrepreneurial opportunity (Shane, 2000). Due to their smallness, startups suffer a structural lack of tangible and intangible resources (McMullen \& Shepherd, 2006; Wymer \& Regan, 2005) and in order to overcome these constraints entrepreneurs attempt to broaden their funding and knowledge bases (Desa \& Basu, 2013; Spender et al., 2017).

From an investor's standpoint a success bias in supporting NVs is quite understandable. Yu (2016) argues that information reduces uncertainty in newly formed businesses; this information has economic value and the willingness to pay for its use will usually depend on the venture's ex-ante success probability (Arora \& Fosfuri, 2005). Funders have the incentive to invest if the probability of success is high enough; therefore, for the sake of the efficacy of a startup's support mechanisms they are required to reduce information and financial gaps between funders and founders. The interest of this research revolves around the performance of FPVs applying to worldwide acceleration programs; these financial organizations invest in cohorts of start-up companies, usually in exchange for equity -typically around $\$ 20,000$ investment for $10 \%$ of the company- (Yu, 2016). After selecting a hand-picked cohort of companies, accelerators run limited-duration programs offering mentorship, education, co-working spaces and culminate in a public pitch event or demo-day. Accelerators become sources of feedback, helping founders to assess the feasibility of the venture's idea. By concentrating resources through seed-funding, access to investment networks, and intensive mentoring, accelerators can identify "winning" ideas more quickly and help NVs grow (Dempwolf et al., 2014, p. 6).

\section{The Measure of FPV's Performance}

Performance measurement is critical to the success of any for-profit organization by creating understanding, moulding behaviour, and improving competitiveness (Gunasekaran et al., 2005). Nonetheless, the performance measurement for emerging SBs is complex with no general accepted criteria (Zinger et al., 2001). In the prestartup stages of entrepreneurship, Gelderen et al. (2005) considered that birth was the first success of nascent firms, while future sound businesses in their early stages, slightly after the start-up phase, but without having achieved a formal structure, require surviving the venture advances in the generation of income, jobs and profit, as a first step towards stability and sustainability (Kazanjian, 1988). At this stage, measures of successful economic performance include: profit generation, cumulative employment generated, and firm-survival times (Bosma et al., 2004; Van de Ven et al., 1984). Given the characteristics of FPVs in the sample in the present study (Bosma et al., 2004), the evolution of the venture's economic development is measured through PERFORMANCE, an ordinal dependent variable (DV) with three levels: the first being "low" which contemplates income generation; the second level is "middle", where in addition to revenue generation, the venture attains objectives such as job creation (over the number of initial founders) or profit generation; the third level is "high" and implies the joint attainment of revenue, employment and earnings.

\section{Critical Success Factors (CSFs) to Be Tested in This Study}

Wronka (2013) argues that CSFs account for the majority of determinants of successful enterprises, thereby having several potential uses for various types of ventures; the effect of the CSFs on the performance of private enterprises is studied by Gunasekaran et al. (2005), Mouzas \& Araujo (2000), and Al-Tit et al. (2019), while the effect on public-private partnerships is studied by Liu et al. (2014).

In particular the effect of CSFs over successful performance of SOVs operating in Israel was extensively examined by Sharir and Lerner (2006); the abovementioned authors considered the following variables based on the four Gartner's entrepreneurial framework dimensions: in the individual dimension, they tested previous experience, total dedication and support by family and friends; under the environmental dimension, public acceptance of the ventures' idea, their social network, their support from other organizations and the funds received were considered; under the organization dimension, the initial budget, the board's governance and the staff's composition were analysed; while under the process dimension, planning, long term cooperation and the market test of the venture's product were introduced. Therefore, taking into account Gartner's (1985) four dimensions, Sharir and Lerner factored their surveyed variables and devised a framework of their own, with eight dimensions that helped explain social entrepreneurial success; i) the entrepreneurs' social network; ii) total dedication to the ventures' success; iii) capital 
base at the establishment stage; iv) acceptance of the ventures' ideas in the public discourse; v) composition of the venturing team, including the ratio of volunteers to salaried employees; vi) forming co-operations in the public and non-profit sectors in the long-term; vii) ability of the service to stand the market test; and viii) the entrepreneurs' managerial experience.

After rejecting the inclusion of factor vi) as it relates specifically to NFPVs and is not applicable, the present research evaluates seven out of the eight Sharir and Lerner's factors known to be conducive to successful social enterprise performance, for the FPVs in the sample. Provided that the data used in this study is secondary, further adjustments were made for the specific conditions of the information collected from the surveys in the 20132018 EDP version. In the present study, the use of these factors is consistent with the explicit social orientation and the acceptance policy of the accelerator programs participating in the GALI initiative; as a matter of fact, nearly nine out of the ten surveyed FPVs in the sample expressed social motivations besides their explicit profit-orientation (2018). In the validation phase of the hypotheses of this study, the above mentioned factors are structured and complemented with the use of variables adapted from the study of for-profit ventures by Gelderen et al. (2005).

At first the proposed factors and variables would be analysed in the sample as a whole in order to test their pertinence and then separately in groups formed by FPVs operating in the LATAM Region and in other countries. This last stage allows us to gain additional insight about possible socio-economic and geographical differential behaviours that could hinder the efficiency of entrepreneurial interventions, paying special attention to Latin America.

\section{Hypotheses Statement}

Regarding the first research question, based on the literature, it is believed in this study, that factors conducive to success proposed by Sharir and Lerner (2006) also have a positive effect on the performance of FPVs participating in the EDP's sample. For that matter, seven of the eight success factors would be tested over the probability of the FPVs' performance enhancement. The resulting first set of seven null hypotheses under validation is shown in Table 1

The Effects of Socio-economic and Geographical Conditions On The Factors Affecting the Success of FPVs

It is known that each economy has, not only its own specific entrepreneurial profile, but firms operating under these settings confront strengths that entrepreneurs can leverage over resource constraints for starting their businesses (Bosma \& Kelley, 2019). In this study, the EDP data is complemented alongside the cited dimension with information related to the Human Capital Index (World Bank, 2019) and the results of the Intergenerational Mobility Report (GDIM, 2018), more specifically the Inter-generational Relative Mobility (IGM); relative IGM is the extent to which an individual's position on the economic scale is independent of the position of his or her parents (in GDIM, it is an individual's years of schooling in relation to his or her parents' years of schooling). Higher relative mobility across generations is associated with lower inequality of opportunity, which is the extent to which people's life achievements are affected by circumstances they are born into, such as parental education and income, race, gender, and birthplace. In particular, this research uses the IGP or relative index of persistence of dependence on mobility, which is the regression coefficient of intergenerational persistence, where high values of the regression coefficient indicate greater persistence of intergenerational persistence, and consequently lower relative mobility (Narayan et al., 2018, p. 74).

Table 1. Research Hypotheses Related to the Effect of Success Factors On the Probability of Fpv's Success In the Whole Sample

\begin{tabular}{cll}
\hline Null Hypotheses & \multicolumn{1}{c}{ Factors } & $\begin{array}{c}\text { Effect on the } \\
\text { thobability of achieving } \\
\text { prigher level of performance }\end{array}$ \\
\hline H1 & The strength of the entrepreneur's social network & Exists and increases the probability \\
H2 & The ability of the service to stand the market test & Exists and increases the probability \\
H3 & The entrepreneur's previous managerial experience & Exists and increases the probability \\
H4 & The acceptance of the venture idea in the public discourse & Exists and increases the probability \\
H5 & The strength of the capital base at the establishment stage & Exists and increases the probability \\
H6 & The dedication to the venture's success by the founders & Exists and increases the probability \\
H7 & The composition of the venturing team & Exists and increases the probability
\end{tabular}

Note: The alternative hypotheses Ha are defined as not Ho. 
Authors such as Zahra et al. (2009), propose that globally, founders take different approaches to recognizing entrepreneurial opportunities; therefore, arrays deriving from these differences might yield diverse results. Regarding these differences, this quest analyses the effect of the success factors under two different geographic settings. Thereby, as per the second research question, the study seeks additional empirical evidence attempting to validate the existence of a differential success behaviour between FPVs operating in the LATAM Region and other countries worldwide, as related to factors having a positive effect on their performance development. The resulting second set of seven null hypotheses is exhibited in Table 2.

\section{Materials and Methods}

The main goal of this research is to empirically investigate the effect of the factors known in the literature to be conducive to successful venture performance, in a sample of FPVs that have either applied and/or advanced from accelerator programs worldwide (Canfield \& Anzola, 2018; Gelderen et al., 2005; Sharir \& Lerner, 2006 ). Specifically, it attempts to measure the magnitude and orientation of such effects over the probability of improving the performance of these ventures. Bearing in mind the scarcity of empirical studies on the subject and the difficulties inherent in gathering first-hand information regarding FPVs on a broad geographic basis, this study acknowledges using data from secondary sources, in particular, information collected through surveys in the Entrepreneurship Database Program at Emory University. The 2013-2018 EDP gathered detailed data from entrepreneurs during their application processes; the questions in the survey structure around four themes: focus and goals, structure and acceptance rates, funding sources, services provided by the accelerator and direct investment (GALI, 2018).

The specific socio-economic and geographical conditions that might complement the said factors were obtained through publicly available information from the World Bank (WB); precisely, information about the human capital index (World Bank, 2019) and the IGP (GDIM, 2018), was collected from those sources, and encoded on a country basis in the EDP.

\section{The Sample}

The 2013-2018 EDP's databases contain information on 19,418 applications of early-stage ventures over 280 different programs run by more than 90 different organizations, in more than 170 countries (GALI, 2018). Given the orientation of the accelerator partners, and the success-bias inherent to participation in entrepreneur support mechanisms, roughly $80 \%$ are for-profit organizations; FPVs were younger on average than the 2,037 non-profit ventures at the time of application to accelerator programs; moreover, in accordance with the impact investment orientation of these acceleration initiatives, $89 \%$ of all ventures declared some sort of social motivation besides profit. As can be expected, the sample exhibits both, a strong social orientation and success biases due to the venture selection process in accelerator programs; as accounted for in the EDP, the sample reflects a strong orientation towards success in its composition, because accelerator programs encourage the participation of enterprises with an established track record

Table 2. Research Hypotheses Related to the Differential Effect of Success Factors On FPVs Operating in the LATAM Region and Other Countries

\begin{tabular}{|c|c|c|}
\hline Null Hypotheses & Factors & $\begin{array}{c}\text { Effect on the } \\
\text { probability of success }\end{array}$ \\
\hline H1A & The strength of the entrepreneur's social network & $\begin{array}{l}\text { Have the same positive } \\
\text { effect on both groups }\end{array}$ \\
\hline $\mathrm{H} 2 \mathrm{~A}$ & The ability of the service to stand the market test & $\begin{array}{l}\text { Have the same positive } \\
\text { effect on both groups }\end{array}$ \\
\hline $\mathrm{H} 3 \mathrm{~A}$ & The entrepreneur's previous managerial experience & $\begin{array}{l}\text { Have the same positive } \\
\text { effect on both groups }\end{array}$ \\
\hline $\mathrm{H} 4 \mathrm{~A}$ & The acceptance of the venture idea in the public discourse & $\begin{array}{l}\text { Have the same positive } \\
\text { effect on both groups }\end{array}$ \\
\hline $\mathrm{H} 5 \mathrm{~A}$ & The strength of the capital base at the establishment stage & $\begin{array}{l}\text { Have the same positive } \\
\text { effect on both groups }\end{array}$ \\
\hline H6A & The dedication to the venture's success by the founders & $\begin{array}{l}\text { Have the same positive } \\
\text { effect on both groups }\end{array}$ \\
\hline $\mathrm{H} 7 \mathrm{~A}$ & The composition of the venturing team & $\begin{array}{l}\text { Have the same positive } \\
\text { effect on both groups }\end{array}$ \\
\hline
\end{tabular}

Note: The alternative hypotheses Ha are defined as not Ho. 
(GALI, 2018, p. 4). Around 16\% of businesses received prior outside equity investment $(14 \%$ debt and $25 \%$ philanthropic investments); half of the ventures report positive revenues in at least one of the previous years, and almost two-thirds report having at least one full or part-time employee at the end of the year (GALI, 2018).

Based on the known features of the sample, an initial sub-sample of 15,417 FPVs on 164 nations (34\% operating in LATAM countries), are studied. As expected, the conformed sub-sample exhibits the same bias as the original one, with respect to the effect of the proven track record as a pre-requisite to participate in the acceleration programs; $28 \%$ of these ventures have been in operation for at least three years, $52 \%$ of them reported operational revenue generation since inception, and $78 \%$ have hired employees beside their founders.

\section{The Operationalization of Success Factors}

The present investigation attempts to validate factors known in the literature to have an influence on the success of FPVs, and at the same time, with the information of the surveys, match the features of the ventures in our sample. The choice of a suitable and practical definition of success in this sample is of outmost importance. In the case of FPVs, mostly in the post-startup phase, Bosma et al. (2004) propose three measures of performance: profit realization, employment generation, and overcoming failure hazard. Its determination in our quest bears in mind important features of the samples due to the bias in the accelerator program's selection processes, such as the main profit-orientation of the companies, their proven track record, their ulterior social motives and the expressed intention of founders to avoid capital restrictions to develop their projects. Given the generality of the survey, the exploratory nature of the study, and the ample representation of FPVs in the sample, in this investigation, the economic evolution of the ventures is measured through PERFORMANCE, an ordinal categorical DV with three levels: "low", which contemplates income generation; "middle", where in addition to revenue generation, the ventures attains objectives such as job creation (a quantity over the number of initial founders) or profit generation; and "high", a level that implies joint attainment of revenue, employment and earnings.

Initially, contemplating the Sharir and Lerner's frame but excluding factor 6 , seven of their eight main factors were matched against information for 30 selected variables encoded in the 2013-2018 EDP. Following the above-mentioned authors, on an exploratory basis, these variables were factored with a dimension-reduction procedure using principal components and an oblique rotation (oblimin), given the possibility that the fac- tors might be related. The initial tests favoured the adequacy of the factor analysis; the value of the KaiserMeyer-Olkin measure of sampling adequacy (KMO) was 0.64 , above the commonly recommended value of 0.6 , suggesting that the sample was factorable; the Bartlett's test for sphericity was highly significant at the $p<0.0001$ level. Thereby, seven components were extracted and the corresponding factors are exhibited in Table 3.

The predictors thought to have an effect on the success of FPVs include those related to the Sharir and Lerner's factors in table 3 and additional classification and control variables, mostly related to the sample or to country specific socio-economic conditions, were included in the OLR model. The variable's definitions are exhibited in table 4.

The independent variables in the OLR model correspond to the seven factors in the framework F1SNETWORK, F2MKTTEST, F3PREVEXP, F4ACCEPTANCE, F5CAPITALBASE, F6DEDICATION and F7TEAMC. Factor 1, relates to the strength of the venture's social network and is operationalized by the factor loadings over variables corresponding to the use of specific social media. Factor 2, the ability to stand the market test is proxied by loadings on the proven operational model of the venture, being packaging, manufacturing, commercial, distribution, whole sale and retail and services. Factor 3, acceptance of the venture's idea in the public's discourse, is represented by the use of Impact Investment Measurement, being Impact Reporting and Investment Standards (IRIS), The Global Impact Investing Rating System (GIIRS) an analogue of the Standard and Poor's or Morningstar rating systems, employing a common set of indicators to measure the social performance of funds and companies that intend to create impact, or other similar measuring systems reported. Factor 4, the total dedication to the venture's operation, is characterized by the interaction between variables defining participation in accelerator programs, selected and finished, as well as a classification variable, survival, reflecting the founder's resilience and initially signalling success in ventures. Factor 5, the strength of the capital base, expressed through variables representing the use of different sources of funding including outside-funding, angel and venture capitalists and bank debt (Gelderen et al., 2005). Factor 6, representing prior entrepreneurial experience, is expressed through measures of intellectual capital as quantified by previous entrepreneurial, managerial, for-profit and non-for profit experience of founders (Lazar et al., 2019). Factor 7 refers to the team's composition where youth represents the coded variable where the mean age of the founders is $<35$ years and the variables Female_presence and found_name1_gender_ 
Table 3. Summary of Exploratory Factor Analysis Results for FPV's Success Dimensions, Using Principal Components Estimation (N=17,084); Obliquely Rotated Component Loadings*

\begin{tabular}{|c|c|c|c|c|c|c|c|}
\hline Item & F1) & F2) & F3) & F4) & F5) & F6) & F7) \\
\hline $\begin{array}{l}\text { Commercial_Model } \\
\text { model_distribution } \\
\text { model_wholretail } \\
\text { model_procpack } \\
\text { model_prodmanuf } \\
\text { Model_Services }\end{array}$ & & $\begin{array}{r}0.91 \\
0.84 \\
0.73 \\
0.74 \\
0.65 \\
-0.67\end{array}$ & & & & & \\
\hline $\begin{array}{l}\text { HC_TEAM_Prior_FP_Ventures } \\
\text { SERIAL } \\
\text { HCTEAM_MGR_EXPQ } \\
\text { HC_TEAM_Prior_NP_Enterprises } \\
\text { nationality_diversity }\end{array}$ & & $\begin{array}{l}0.91 \\
0.90 \\
0.61 \\
0.52\end{array}$ & & & & & \\
\hline $\begin{array}{l}\text { FUND_Outside_funding } \\
\text { FUND_inv_equityfrom_angels } \\
\text { FUND_Bank_debt_investment } \\
\text { E_VC }\end{array}$ & & & & $\begin{array}{l}0.91 \\
0.72 \\
0.53 \\
0.52\end{array}$ & & & \\
\hline $\begin{array}{l}\text { selected } \\
\text { finished }\end{array}$ & & & & & $\begin{array}{l}0.92 \\
0.91\end{array}$ & & \\
\hline $\begin{array}{l}\text { Female_presence } \\
\text { found_name1_gender_coded } \\
\text { youth }\end{array}$ & & & & & & $\begin{array}{l}0.71 \\
0.70\end{array}$ & \\
\hline
\end{tabular}

Notes: *Loadings $=>$.4; F1: Strength of social network; F2 Ability to stand market test; F3 Public acceptance of the venture's idea; F4 Dedication; F5 capital base; F6 Previous experience; F7 Team Composition.

coded represent diversity in perspectives due to female leadership in the founder's team (Carter et al., 2003).

Classification and control factors include: internationalization, a variable characterizing those ventures that operate in a different geographic setting from their headquarters' location; the QuartIGP attempts to capture the efforts of founders to overcome socio-demographic constraints at the geographic or regional level; this variable is coded 1 to 4 , where 4 is the lowest quartile of intergenerational persistence with higher relative mobility; IC_model_invention_based represents the technological content of the venture; the control variable SIZE represents the number of employees and captures such effect and the interaction WORTH\#WB_SMESIZE deals with the overall complexity of managing the venture.

\section{Descriptive Statistics for Variables in the Model}

The summary statistics for the variables in the model are shown in table 5 .

\section{The OLR Model}

Ordered logit models are used to estimate relationships between an ordinal dependent variable (DV) -the response-, and a set of independent variables or predictors; an ordinal variable is a categorical and ordered variable. In this case, the response variable is PERFORMANCE, taking values of "low", "middle" and "high", with an improvement progression. In ordered logit, an underlying score is estimated as a linear function of the independent variables and a set of cut-points. The probability of observing outcome $i$ corresponds to the probability that the estimated linear function, plus random error, is within the range of the cut-points estimated for the outcome: $\operatorname{Pr}$ (outcome $\left._{j}=\mathrm{i}\right)=\operatorname{Pr}\left(\kappa_{\mathrm{i}-1}<\beta_{1 \times 1 j}+\beta_{2 \times 2 \mathrm{j}}+\right.$ $\cdots+\beta_{\text {kxkj }}+u_{j} \leq \kappa_{\mathrm{i}}$ ) where $u_{\mathrm{j}}$ is assumed to be logistically distributed in ordered logit. In either case, we estimate the coefficients $\beta_{1}, \beta_{2},::: \beta_{\mathrm{k}}$ together with the cut-points $\kappa_{1}, \kappa_{2},:::, \kappa_{\mathrm{k}-1}$, where $\mathrm{k}$ is the number of possible outcomes. $\kappa_{0}$ is taken as $-\infty$, and $\kappa_{\mathrm{k}}$ is taken as $+\infty$. 
Table 4. Operationalization of FPV's Success Factors



Notes: + F1: Strength of social network; F2 Ability to stand market test; F3 Public acceptance of the venture's idea; F4 Dedication; F5 capital base; F6 Previous experience; F7 Team Composition; Class, Classification variables related to the FPV's conditions in the sample.

All of this is a direct generalization of the ordinary twooutcome logit model (StataCorp, 2013, p. 1531). The equation coefficients quantify the effect of the predictors over the log-odds ratio; the interpretation of the ordered logit coefficient is that for a one unit increase in the predictor, the response variable level is expected to change by its respective regression coefficient in the ordered logodds scale while the other variables in the model are held constant. When the odds-ratio is one, no association between the variables is found; values less than one imply a 
Table 5. Descriptive Statistics for Variables in the OLR Model

\begin{tabular}{|c|c|c|c|c|c|c|}
\hline$\#$ & Variable & Obs & Mean & Std. Dev. & Min & Max \\
\hline 1 & selected & 17,084 & 0.11 & 0.31 & 0.00 & 1.00 \\
\hline 3 & QuartIGP & 17,084 & 2.52 & 1.10 & 1.00 & 4.00 \\
\hline 4 & survival & 17,084 & 0.32 & 0.51 & 0.00 & 1.00 \\
\hline 6 & SC_website & 17,084 & 0.70 & 0.51 & 0.00 & 1.00 \\
\hline 7 & SC_has_facebook & 17,084 & 0.67 & 0.51 & 0.00 & 1.00 \\
\hline 8 & SC_has_twitter & 17,084 & 0.42 & 0.52 & 0.00 & 1.00 \\
\hline 9 & SC_has_linkedin & 17,084 & 0.33 & 0.43 & 0.00 & 1.00 \\
\hline 13 & model_procpack & 17,084 & 0.12 & 0.42 & 0.00 & 1.00 \\
\hline 14 & model_distribution & 17,084 & 0.23 & 0.44 & 0.00 & 1.00 \\
\hline 15 & model_wholretail & 17,084 & 0.25 & 0.42 & 0.00 & 1.00 \\
\hline 16 & Commercial_Model & 17,084 & 0.33 & 0.53 & 0.00 & 1.00 \\
\hline 17 & Model_Services & 17,084 & 0.71 & 0.43 & 0.00 & 1.00 \\
\hline 18 & IC_model_invention_based_model & 17,084 & 0.52 & 0.52 & 0.00 & 1.00 \\
\hline 19 & WB_SMESIZE & 17,084 & 1.21 & 0.43 & 1.00 & 4.00 \\
\hline 25 & HC_TEAM_Prior_NP_Enterprises & 17,084 & 0.53 & 1.02 & 0.00 & 4.00 \\
\hline 26 & SERIAL & 17,084 & 0.34 & 0.43 & 0.00 & 1.00 \\
\hline 27 & prior_accelerator_experience & 17,084 & 0.33 & 0.52 & 0.00 & 1.00 \\
\hline 28 & youth & 17,084 & 0.65 & 0.52 & 0.00 & 1.00 \\
\hline 29 & Female_presence & 17,084 & 0.8 & 0.43 & 0.00 & 1.00 \\
\hline 30 & nationality_diversity & 17,084 & 0.1 & 0.44 & 0.00 & 1.00 \\
\hline 31 & found_name1_gender_coded & 17,084 & 0.36 & 0.51 & 0.00 & 1.00 \\
\hline 32 & SIZE & 17,084 & 1.08 & 0.10 & 1.00 & 2.00 \\
\hline 33 & WORTH & 17,084 & 2.52 & 1.11 & 1.00 & 4.00 \\
\hline 34 & F1SNETWORK & 17,084 & $3.1 \mathrm{E}-17$ & 1.01 & -1.71 & 2.01 \\
\hline 35 & F2MKTTEST & 17,084 & $-5.2 \mathrm{E}-17$ & 1.04 & -1.01 & 2.61 \\
\hline 36 & F3PREVEXP & 17,084 & $-5.9 \mathrm{E}-17$ & 1.03 & -1.41 & 3.07 \\
\hline 37 & F4ACCEPTANCE & 17,084 & $-2.9 \mathrm{E}-17$ & 1.04 & -1.11 & 3.21 \\
\hline 38 & F5CAPITALB E & 17,084 & $7.6 \mathrm{E}-17$ & 1.12 & -1.22 & 5.11 \\
\hline 39 & F6DEDICATION & 17,084 & $5.7 \mathrm{E}-18$ & 1.21 & -0.91 & 3.04 \\
\hline 40 & F7TEAMC & 17,084 & $-1.9 \mathrm{E}-17$ & 1.02 & -3.41 & 3.21 \\
\hline
\end{tabular}


negative association, whereas values greater than one imply positive association.

\section{Estimation Results}

For the purpose of testing our hypotheses, Table 6 reports the results from the $O L R$ model, with PERFORMANCE being the response variable. All estimated coefficients are significant at the $0.1 \%$ level, with the exception of the following variables: F4ACCEPTANCE (Factor 4) and F7TEAMC (Factor 7), which are significant at the 5\% level and F6DEDICATION (Factor 6) which is significant at the $10 \%$ level; the five interactions WORTH\#WB SMESIZE [1,2], [2,2], [3,2], [4,1] and [4,2] were also found significant.

The global model is appropriate; its overall significance measured through the value of the likelihood ratio LR chi 2(26) is 3,986 with a probability > chi 2 of 0 ; The pseudo-R2 of the model is 0.29 ; a possible misspecification using the linktest command in STATA ${ }^{\mathrm{TM}}$ proved not significant at the 5\% level. For that matter the probability of improving performance of an FPV can be obtained through the following OLR model, reported in coefficients (ln of odds-ratios)

PERFORMANCE $=-0.08 F 1+0.2 F 2+0.2 F 3+0.06 F 4+0$. $3 F 5+0.05 F 6-0.07 F 6-0.7$ Internationalization $+\ldots$

- 0.3QuartIGP + 0.3 survival +3.1 SIZE $+3.9\left[\begin{array}{ll}1 & 2\end{array}\right]+$ $4.2[22]+4.05[32]+0.32[41]+3.8[42]$ (1)

For the sake of clarity, Table 7 summarizes the first OLR model as it relates to the first set of seven hypotheses tested.

For the whole sample, the first set of hypotheses tested, $\mathrm{H} 1$ through $\mathrm{H} 7$, are those about the conduciveness to success of the seven factors in the framework; in our case $B i$ 's associated with Factors 1 through 7 are statistically different from 0 at a significance level of $10 \%$; nevertheless, the coefficients of Factors 1 and 7 are negative; the model's null hypotheses $\mathrm{H} 2$ through $\mathrm{H} 6$ are rejected in favour of validating the existence of a positive effect over success of the Factors 2 through 6.

The reason for the negative sign in both factors F1 and F7, might reside in the limitations of the study that uses secondary sources and in the expressed EDP sample's bias; specifically regarding F1, the true importance of

Table 6. Summary of OLR's Analysis of Variables Predicting FPVs' Performance. The General Model

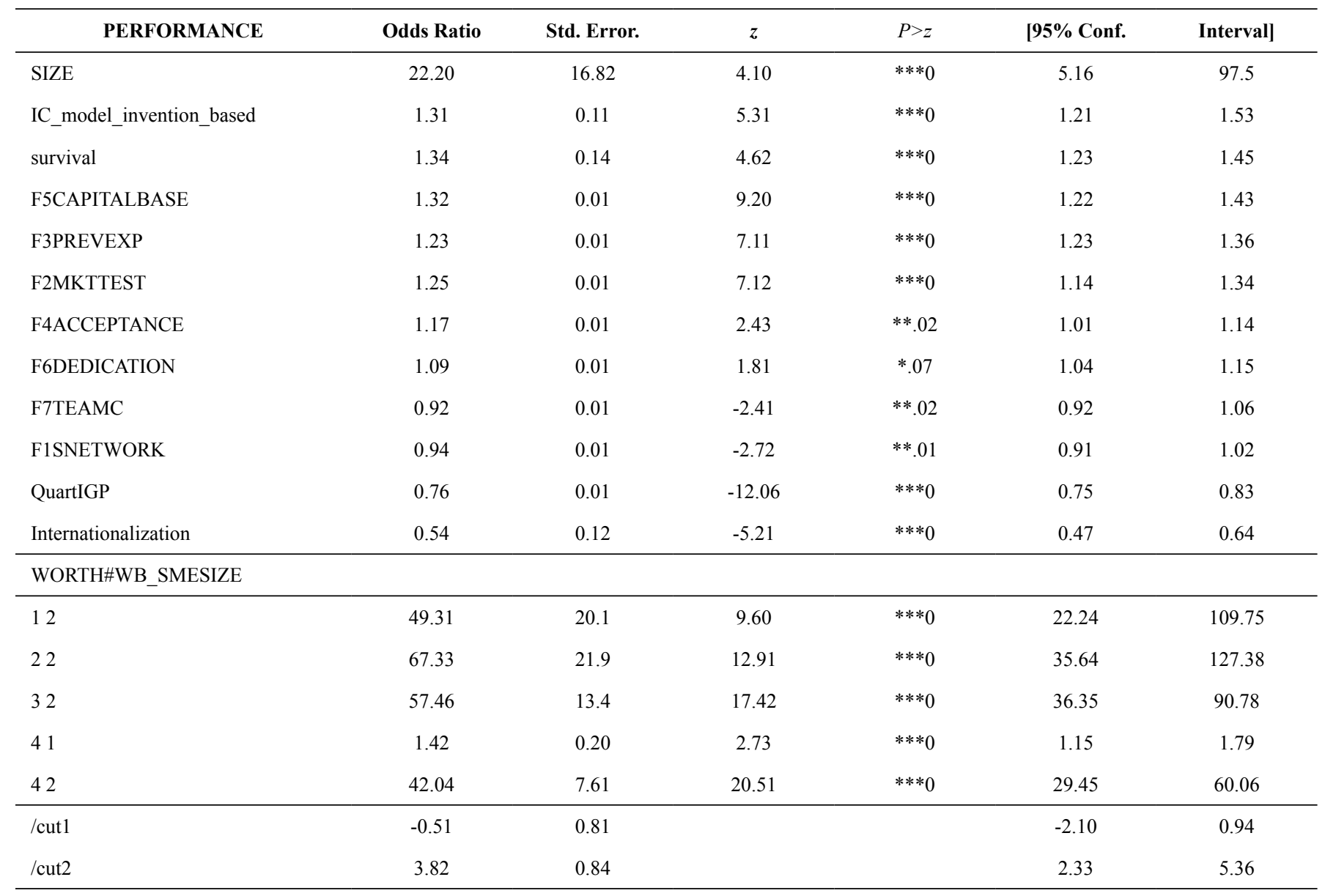

Notes: $* p<0.10 ; * * p<0.0 ; * * * p<0.001$ 
Table 7. Summary of Ordinal Logistic Regression Analysis by Means of Validated Hypotheses in the study (First Set of Hypotheses)

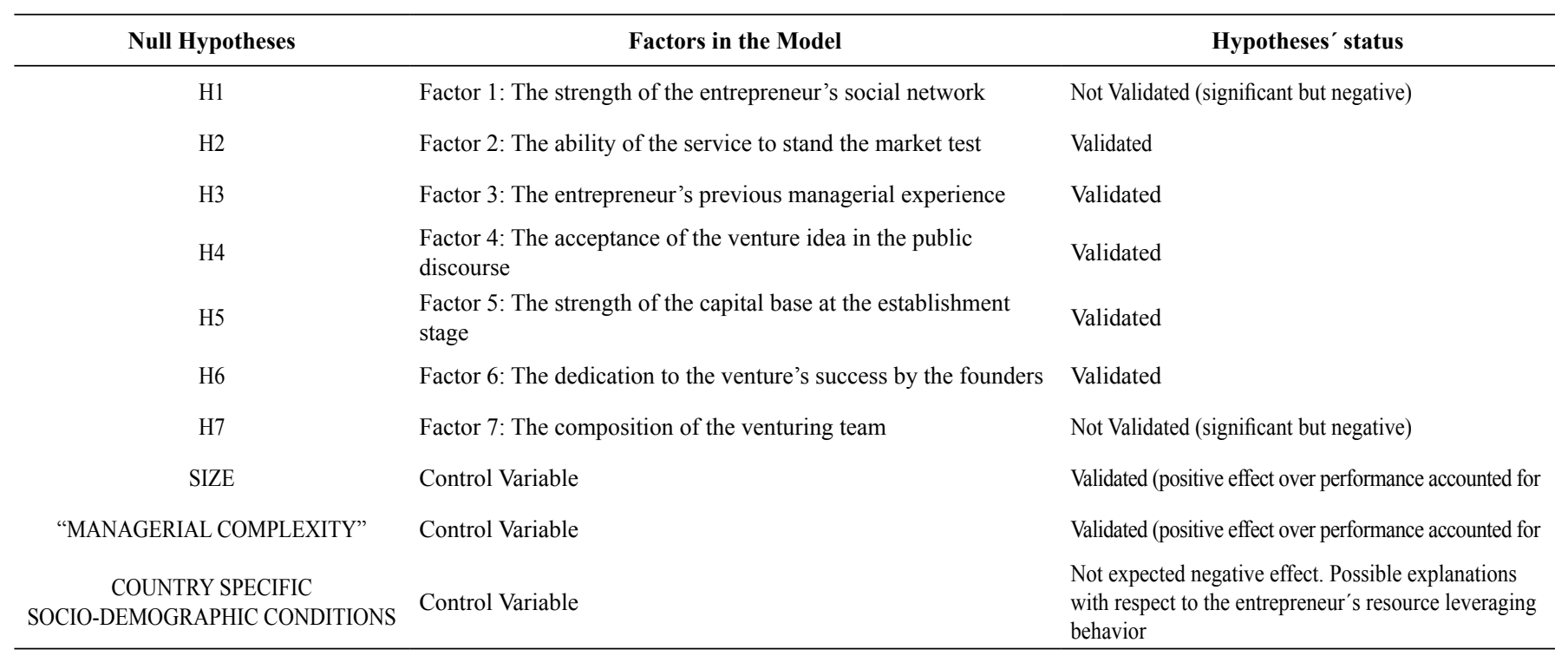

the FPVs' social networks may not necessarily reside in the use of social media to outreach investors and attract business opportunities; moreover, it may possibly be that participation in accelerator programs outgrows the possibilities of social media for connecting with targeted audiences; notwithstanding, not having the opportunity to formulate that question directly, one can pay attention to outside funding (AFs, VCs and equity funding) as both, a funding source and a signal for bridging funding and information gaps in the future. Respective to the negative sign in F7, there is a great possibility that the EDP's bias regarding gender diversity contributes to the explanation; as reported, female founders worldwide have a lower probability of raising capital, however, their ventures tend to generate early operational revenues (GALI, 2018); moreover, the age-effect is not strong and this is partially due to the fact that, as mentioned above, the mean age for the FPVs in the sample is smaller than the overall figure.

After controlling by size and managerial complexity of the FPVs, the negative signs around geographical conditions strike our attention; operating in other countries different from the head-quarters' location could be considered either difficult in itself or might not truly reflect the venture's operating conditions, possibly being one of the limitations of the study. The magnitude of the equation's coefficient for QuartIGP, measure of inequality of opportunities, is very important; moreover, socioeconomic variables, such as the Human Capital Index, the World Bank's Economic classification of countries, and others included in the preliminary phases of the model, yielded the same negative coefficients. Bosma and Kelley (2019) have provided explanations in other contexts that could be applied here; entrepreneurs in underprivileged markets may take additional efforts to overcome constraints with creative solutions, nevertheless such limitations exist and need to be overcome, as well as sample bias where accelerators normally accept only well established and successful ventures from the beginning.

As per the second set of hypotheses, they test for differential success behaviour of FPVs operating in Latin America and other countries; the study attempts to find a dissimilar international impact of success factors derived from specific socio-economic and cultural conditions. For that matter the same OLR model was fitted by groups, being one for those FPVs participating in the LATAM Region and another for the rest of the world.

Predictor variables considered to be conducive to performance enhancement for our cases, as well as their effect on the odds ratio, are exhibited in Table 8.

Both models are appropriate; their overall significance measured through the values of the likelihood ratio LR chi 2(26) is 2723 with a probability $>$ chi 2 of 0 for the rest of the world model and 1309, with a probability $>$ chi 2 of 0 for the LATAM Region model. The pseudo-R2 are 0.29 and 0.33 respectively; also a possible misspecification using the linktest command in STATA ${ }^{\mathrm{TM}}$ proved not significant at the 5\% level.

For the sake of clarity, Table 9 summarizes the OLR model as it relates to the second set of seven hypotheses tested.

Using the same OLR model as that one in equation 1 , in the groups formed by FPVs with operations in the Latin America, it was found that only Factor 3, Factor 5 and Factor 6 were positive and significant at the 5\% level. Surprisingly enough, the socioeconomic variable QuartIGP was also found significant and its effect was positive. The magnitude of the coefficient of survival is 
Table 8. Summary of OLR's Analysis of Variables Predicting FPVs' Performance in the LATAM and Rest of the World's Models

\begin{tabular}{|c|c|c|c|c|c|c|c|c|}
\hline Rest of the world Model & & & & & & & LATAN & Model \\
\hline F1SNETWORK & Neg. & 0.91 & -2.20 & $* * 0.03$ & NS & 1.02 & & NS \\
\hline F2MKTTEST & Pos. & 1.32 & 6.61 & $* * * 0$ & NS & 1.12 & & NS \\
\hline F3PREVEXP & Pos. & 1.23 & 6.20 & $* * * 0$ & Pos. & 1.23 & 2.81 & $* * 0.01$ \\
\hline F5CAPITALBASE & Pos. & 1.32 & 8.31 & $* * * 0$ & Pos. & 1.21 & 4.31 & $* * * 0$ \\
\hline F6DEDICATION & Pos. & 1.17 & 1.91 & $* * 0.05$ & Pos. & 1.14 & 2.23 & $* * 0.03$ \\
\hline F7TEAMC & NS & 1.06 & & NS & NS & 1.01 & & NS \\
\hline Internationalization & Neg. & 0.41 & -5.20 & $* * * 0$ & NS & 0.72 & & NS \\
\hline survival & Pos. & 1.12 & 2.11 & $* * 0.04$ & Pos. & 1.95 & 5.94 & $* * * 0$ \\
\hline SIZE & NS & 0.01 & & NS & Pos. & 9.14 & & $* * 0.01$ \\
\hline \multicolumn{9}{|l|}{ WORTH\#WB_SMESIZE } \\
\hline 12 & Positive & 35.91 & 7.92 & $* * * 0$ & Pos. & 152.41 & 4.91 & $* * * 0$ \\
\hline 21 & NS & 0.01 & & NS & Neg. & 0.72 & & $* 0.07$ \\
\hline 22 & Pos. & 52.91 & 11.12 & $* * * 0$ & Pos. & 118.84 & 6.42 & $* * * 0$ \\
\hline 32 & Pos. & 53.72 & 14.23 & $* * * 0$ & Pos. & 64.12 & 9.01 & $* * * 0$ \\
\hline 41 & Pos. & 1.32 & 1.82 & $* 0.08$ & Pos. & 1.93 & 2.92 & $* * 0.01$ \\
\hline
\end{tabular}

Notes: ${ }^{*} p<0.10 .{ }^{* *} p<0.05 ;{ }^{* *} p<0.00$; NS, not significant.

quite, important; resilient companies have almost twice as much opportunity to enhance their performance than those who actually fail by the third year milestone. SIZE and the managerial complexity effects have a special impact over the probabilities of performance development, especially when compared with firms in the rest of the world; the effect of the technological base of the ventures is moderate as compared with the other factors. Factors one, two and four, were reported as non-significant in the estimation. The effect of factors one and seven can be related to the explanation in the general model; Factor 4 deals with the point that impact measurement systems may not be well established in the region and the fact that there might be other measures that were not surveyed in the EDP. The results in the model for the rest of the world are consistent with those in the LATAM model, the exception being internationalization; this can be explained in the same tenor as the original model.
Surprisingly, the effects of the size and the complexity interactions, and the resilience variables in this model are roughly half the values of the LATAM's model and the effects of Factor 1 and 7 are consistent with the general model's explanation.

\section{Discussion and Final Remarks}

As per different conditions and economic contributions, as posted in the literature, small new businesses worldwide, in their own right, constitute themselves as economic drivers for the future; having survived their founding stage, they contribute to the creation of jobs, sales and exports in many regions. Under an entrepreneurial perspective they introduce innovation, create disruption, increase competition and enhance rivalry among all economic agents. Nevertheless these ventures face many constraints, not only in unprivileged settings but almost everywhere; with 
Table 9. Summary of Ordinal Logistic Regression Analysis by Means of Validated Hypotheses in the Study (Second Set of Hypotheses)

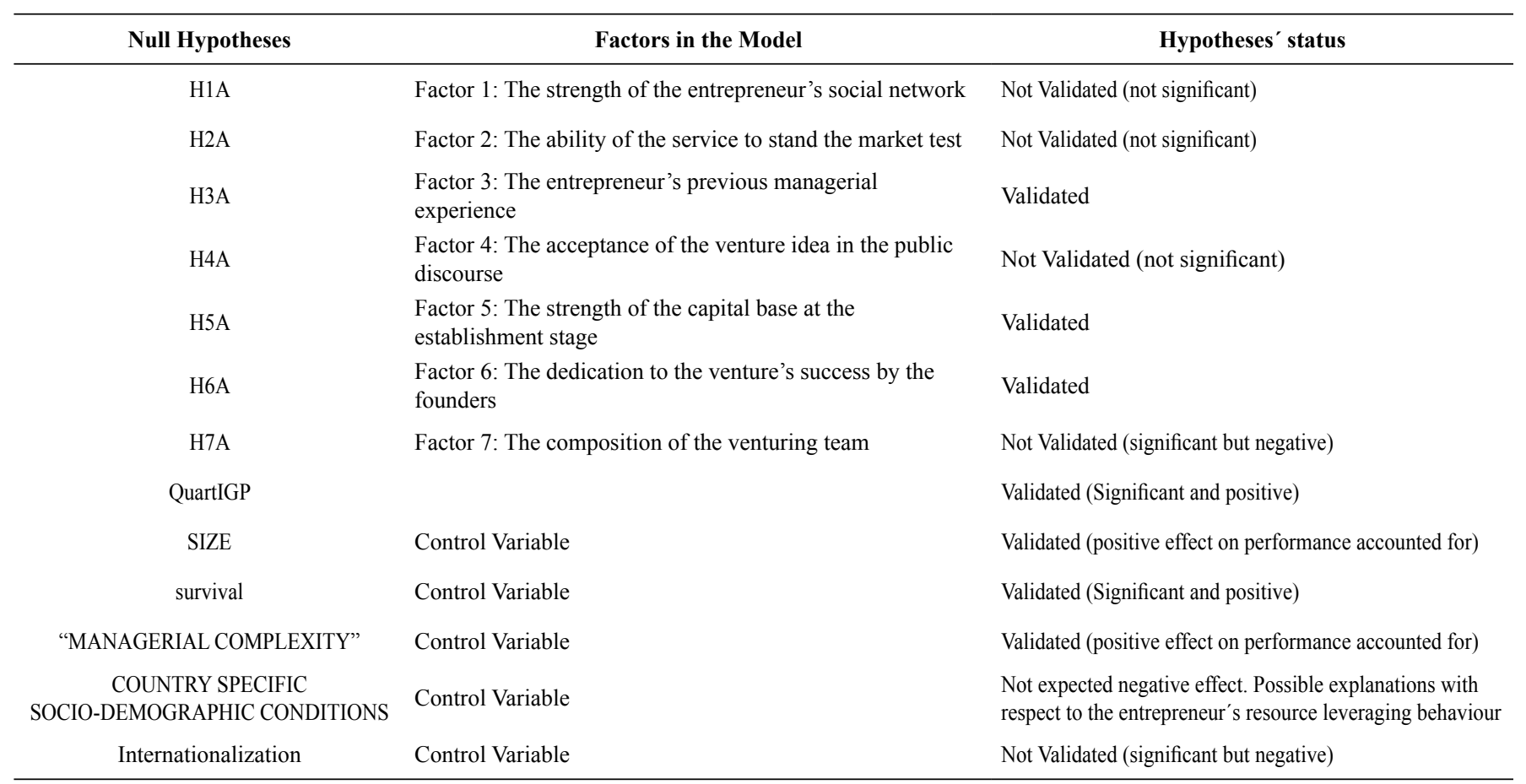

different rates of success, support mechanisms stemmed from government and private-sector sponsorship help them overcome many restrictions in their initial stages. Accelerators have contributed to their development by bridging many funding and information gaps that otherwise limit their opportunities.

Given the documented fragility of new businesses, there is a clear need for systematic knowledge about how well these support mechanisms contribute to the development of the entrepreneurial eco-system. Shedding some light on contributing factors of economic performance seems like a small but strong step in the right direction. Besides inherent limitations to the use of secondary information and even though this study is circumscribed to FPVs applying to accelerator programs, the wide geographic base of the EDP sample provides us with new possibilities in the future to learn about the development of NVs development. Thereby, what have we learned from this exercise?

After the partial validation of the effect of a set of CSFs in the economic performance of a broad range of FPVs, we can pinpoint many things. Firstly, in our sample, even after having considered the success bias that characterizes the acceptance policy of accelerator programs, and controlled by size and managerial complexity of the venture, it was found that FPVs worldwide, with the aid of these much needed support mechanisms, must focus on: strengthening their capital base and appeal to a wider audience of investors and funders, aim to expand the founder's human capital as it relates to job and managerial experience, develop mechanisms for strategic acquisition of intellectual capital stocks, adopt business models with proven track records, use certifications and sustainability and impact measurement systems in order to reduce search and transaction costs, bridge the funding and information gaps, compensate for costly reputation-building mechanisms for instituting business networks instead of adversary relations, and most importantly, the above mentioned support mechanisms must provide the necessary tools for business survival in the early stages of NVs.

Secondly, this research highlights the fact that, even though FPVs in the LATAM region are affected by almost the same factors as their counterparts in the rest of the world, there is a differential behaviour that translates into a different perspective for support policies. For one thing, it strikes out that ventures in the LATAM region, where not only economic but also education inequality reign, have learned to operate in underprivileged conditions; this is not to say that institutional developments and a more levelled ground are not required. It was proven in the study that after having controlled for size and managerial complexity, the probabilities of performance development in FPVs in the region almost double if they survive their initial constraints; moreover, the effects of resource availability as it relates to financial and human capital improve their probabilities to enhance their performance. The same can be said about the effect of dedication and resilience, in particular the positive effect of support mechanisms such as accelerating programs 
participation, as well as a sound technological base which improve the probabilities of attaining better performance results of FPVs in the sub-sample.

Thirdly, even though it has not been possible to appraise systematically the efficacy of accelerator programs due to information limitations, some general considerations are highlighted. Aside from cultural and socioeconomic differences, that would certainly account for the specificity of the problems confronted by FPVs and for disparities in the dedication and the efficacy of individual entrepreneurial resources applied in their solution, the assurance of globalized and homogeneous selection processes in acceleration and other support programs, as well as the use of sound standard performance measures, such as those derived from impact investment methodologies, have a positive influence on FPVs. This contention leverages plenty of academic and practical prospects for exploring the influence of socio-economic and cultural influences over the efficacy of startups and SBSs' interventions. After controlling for efficiency in the disposition of entrepreneurial resources, the organizations based on government, market and civil society sectors can allocate their attention to those country specific situations, affecting the efficacy of development programs such as the problems to be solved, the particular eco-systems, and the suitability of the organizational arrays adopted.

And lastly, the present research continues to reduce the gap on empirical studies related to success in FPVs with the use of rich longitudinal datasets, based on multi-purpose surveyed data. It is quite clear that given the expressed bias in the figures collected, generalization beyond the sample is not straightforward. Nevertheless, this study leads the way for supplementary clarification regarding the incidence of specific socio-economic and multicultural factors affecting the effectiveness of international partnering efforts, based on entrepreneurship support, to provide solutions to specific compelling problems in all societies and to create economic growth and sustainable development by reinforcing global efficiency standards and procedures in developing programs around the world.

\section{References}

Acs, Z., \& Amorós, J. (2008). Entrepreneurship and competitiveness dynamics in Latin America. Small Business Economics, 31(3), 305-322.

Acs, Z., \& Stough, R. (2008). Introduction to public policy in an entrepreneurial society. In Public Policy in an Entrepreneurial Economy (pp. 1-22). Springer.

Acs, Z., Braunerhjelm, P., Audretsch, D., \& Carlsson, B. (2009). The knowledge spillover theory of entrepreneurship. Small Business Economics, 32(1), 15-30.
Aldrich, H., \& Ruef, M. (2018). Unicorns, gazelles, and other distractions on the way to understanding real entrepreneurship in the United States. Academy of Management Perspectives, 32(4), 458-472.

Al-Tit, A., Omri, A., \& Euchi, J. (2019). Critical success factors of small and medium-sized enterprises in Saudi Arabia: Insights from sustainability perspective. $A d$ ministrative Sciences, 9(2).

Alvarez, S., \& Barney, J. (2014). Entrepreneurial opportunities and poverty alleviation. Entrepreneurship Theory and Practice, 8(1), 159-184.

Arora, A., \& Fosfuri, A. (2005). Pricing diagnostic information. Management Science, 51(17), 1092-1100.

Audretsch, D., Santarelli, E., \& Vivarelli, M. (1999). Start-up size and industrial dynamics: Some evidence from Italian manufacturing. International Journal of Industrial Organization, 17(7), 965-983.

Bartelsman, E., Scarpetta, S., \& Schivardi, F. (2005). Comparative analysis of firm demographics and survival: Evidence from micro-level sources in OECD countries. Industrial and Corporate Change, 14(3), 365-391.

Baumol, W., \& Strom, R. (2007). Entrepreneurship and economic growth. Strategic entrepreneurship journal, 1(3-4), 233-237.

Birch, D. (1979). The job generation process. MIT Program on Neighborhood and Regional Change.

Bosma, N., \& Kelley, D. (2019). GEM GLOBAL Report 2019. Global Economic Monitor.

Bosma, N., Van Praag, M., Thurik, R., \& De Wit, G. (2004). The value of human and social capital investments for the business performance of startups. Small Business Economics, 23(3), 227-236.

Boynton, A., \& Zmud, R. (1984). An assessment of critical success factors. Sloan Management Review, 25(4), 17-27.

Bruno, A., Leidecker, J., \& Harder, J. (1987). Why firms fail. Business Horizons, 30(2), 50-58.

Canfield, C., \& Anzola, E. (2018). Successful performance in socially oriented ventures stemming from international accelerator programs: A comparative study between OECD and developing countries. Independent Journal of Management \& Production, 9(4).

Carree, M., \& Thurik, A. (2010). The impact of entrepreneurship on economic growth. En(In) Handbook of entrepreneurship research (pp. 557-594). Springer.

Carter, N., Brush, C., Greene, P., Gatewood, E., \& Hart, M. (2003). Women entrepreneurs who break through to equity financing: the influence of human, social and financial capital. Venture Capital: An international journal of entrepreneurial finance, 5(1). 
Cohen, S. (2013). What do accelerators do? Insights from incubators and angels. Innovations: Technology, Governance, Globalization, 8(3-4), 19-25.

Cohen, S., \& Hochberg, Y. (2014). Accelerating startups: The seed accelerator phenomenon. SSRN Electronic Journal, (March), 1-16.

Cooper, A. (1993). Challenges in predicting new firm performance. Jounal of business venturing, 8(3), 241-253.

Delmar, F., Davidsson, P., \& Gartner, W. (2003). Arriving at the high-growth firm. Journal of business venturing, 18(2), 189-216.

Dempwolf, C., Auer, J., \& D'Ippolito, M. (2014). Innovation accelerators: Defining characteristics among startup assistance organizations. Small Business Administration.

Desa, G., \& Basu, S. (2013). Optimization or bricolage? Overcoming resource constraints in global social entrepreneurship. Strategic Entrepreneurship Journal, 7(1), 26-49.

Duchesneau, D., \& Gartner, W. (1990). A profile of new venture success and failure in an emerging industry. Journal of Business Venturing, 5(5), 297-312.

Fishback, B., Gulbranson, C., Litan, R., Mitchell, L., \& Porzig, M. (2007). Finding business' idols': A new model to accelerate start-ups. SSRN Electronic Journal.

GALI. (2018). The entrepreneurship database program 2018 data summary. 30 September (septiembre), 2019. Global Accelerator Learning Initiative GALI. https:// www.galidata.org/publications

Gartner, W. (1985). A conceptual framework for describing the phenomenon of new venture creation. Academy of Management Review, 10(4), 696-706.

GDIM. (2018). Global Database on Intergenerational Mobility. World Bank Group. World Bank Development Research Group.

Gelderen, M., Thurik, R., \& Bosma, N. (2005). Success and risk factors in the pre-startup phase. Small Business Economics, 24(4), 369-380.

Gonzalez-Uribe, J., \& Leatherbee, M. (2017). The effects of business accelerators on venture performance: Evidence from start-up Chile. The Review of Financial Studies.

Gunasekaran, A., Williams, H., \& McGaughey, R. (2005). Performance measurement and costing system in new enterprise. Technovation, 25(5), 523-533.

Hagedoorn, J. (1996). Innovation and entrepreneurship: Schumpeter revisited. Industrial and Corporate Change, 5(3), 883-896.

Hall, J., \& Sobel, R. (2008). Institutions, entrepreneurship, and regional differences in economic growth. Southern Journal of Entrepreneurship, 1(1), 69-96.
Hallen, B., Bingham, C., \& Cohen, S. (2014). Do accelerators accelerate? A study of venture accelerators as a path to success? In A. o. Management (Ed.), Academy of Management Proceedings, 2014(1), 12955.

Headd, B. (2003). Redefining business success: Distinguishing between closure and failure. Small Business Economics, 21(1), 51-61.

Helfat, C., \& Lieberman, M. (2002). The birth of capabilities: Market entry and the importance of pre-history. Industrial and Corporate Change, 11(4), 725-760.

Kazanjian, R. (1988). Relation of dominant problems to stages of growth in technology-based new ventures. Academy of Management Journal, 31(2), 257-279.

Lazar, M., Miron-Spektor, E., Agarwal, R., Erez, M., Goldfarb, B., \& Chen, G. (2019). Entrepreneurial team formation. Academy of Management Annals Forthcoming.

Lehmann, E., \& Schenkenhofer, J. W. (2019). Hidden champions and unicorns: A question of the context of human capital investment. Small Business Economics, 52(2), 359-374.

Liu, J., Love, P., Davis, P., Smith, J., \& Regan, M. (2014). Conceptual framework for the performance measurement of public-private partnerships. Journal of Infrastructure Systems, 21(1).

Lumpkin, G., \& Dess, G. (1996). Clarifying the entrepreneurial orientation construct and linking it to performance. Academy of Management Review, 21(1), 135-172.

Lynch, R. (2003). Corporate strategy (3rd ed.). Prentice Hall.

McMullen, J., \& Shepherd, D. (2006). Entrepreneurial action and the role of uncertainty in the theory of the entrepreneur. Academy of Management Review, 31(1), 132-152.

Miller, D., \& Friesen, P. (1982). Structural change and performance: Quantum versus piecemeal-incremental approaches. Academy of Management Journal, 25(4), 867-892.

Morris, M., Kuratko, D., \& Cornwall, J. (2013). Entrepreneurship programs and the modern university. Edward Elgar Publishing.

Morris, M., Neumeyer, X., \& Kuratko, D. (2015). A portfolio perspective on entrepreneurship and economic development. Small Business Economics, 45(4), 713-728.

Morris, M., Neumeyer, X., Jang, Y., \& Kuratko, D. (2018). Distinguishing types of entrepreneurial ventures: An identity-based perspective. Journal of Small Business Management, 56(3), 453-474. 
Mouzas, S., \& Araujo, L. (2000). Implementing programmatic initiatives in manufacturer-retailer networks. Industrial Marketing Management, 29(4), 293-302.

Narayan, A., Van der Weide, R., Cojocaru, A., Lakner, C., Redaelli, S., Mahler, D. G., . . . Thewissen, S. (2018). Fair progress? Economic mobility across generations around the world. Equity and development. World Bank.

Phan, P., Siegel, D., \& Wright, M. (2005). Science parks and incubators: Observations, synthesis and future research. Journal of Business Venturing, 20(2), 165-182. not in the text

Phillips, B., \& Kirchhoff, B. (1989). Formation, growth and survival; small firm dynamics in the US economy. Small Business Economics, 1(1), 65-74.

Radojevich-Kelley, N., \& Hoffman, D. (2012). Analysis of accelerator companies: An exploratory case study of their programs, processes, and early results. Small Business Institute Journal, 8(2), 54-70.

Reynolds, P. (1987). New firms: Societal contribution versus survival potential. Journal of Business Venturing, 2(3), 231-246.

Rockart, J. (1979). Chief executives define their own data needs. Harvard Business Review, 57(2), 81-93.

Schumpeter, J. (1934). The theory of economic development. Translated by Redvers Opie. Harvard Economic Studies.

Shane, S. (2000). Prior knowledge and the discovery of entrepreneurial opportunities. Organization Science, 11(4), 448-469.

Shane, S. (2003). A general theory of entrepreneurship: The individual-opportunity nexus. Edward Elgar Publishing. not in the text

Shane, S. (2009). Why encouraging more people to become entrepreneurs is bad public policy. Small Business Economics, 33(2), 141-149.

Sharir, M., \& Lerner, M. (2006). Gauging the success of social ventures initiated by individual social entrepreneurs. Journal of World Business, 41(1), 6-20.

Spender, J., Corvello, V., Grimaldi, M., \& Rippa, P. (2017). Startups and open innovation: A review of the literature. European Journal of Innovation Management, 20(1), 4-30.

Stangler, D. (2010). High-growth firms and the future of the American economy. Kauffman Foundation.

StataCorp. (2013). Stata: Release 13. Statistical Software. College Station, TX: StataCorp LP.

Storey, D. (1994). Understanding the small business sector. Routledge.
Thurik, R., \& Wennekers, S. (2004). Entrepreneurship, small business and economic growth. Journal of Small Business and Enterprise Development, 11(1), 140-149.

Trivedi, C., \& Stokols, D. (2011). Social enterprises and corporate enterprises: Fundamental differences and defining features. The Journal of Entrepreneurship, 20(1), 1-32. not in the text

Van de Ven, A., Hudson, R., \& Schroeder, D. (1984). Designing new business startups: Entrepreneurial, organizational, and ecological considerations. Journal of Management, 10(1), 87-108.

Van Stel, A., Carree, M., \& Thurik, R. (2005). The effect of entrepreneurial activity on national economic growth. Small Business Economics, 24(3), 311-321.

Vesper, K. (1980). New venture planning. Journal of Business Strategy, 1( 2), 73-75.

Walker, R. (2018). Tech city: Myths of Silicon Valley and globalization. In Annales de geographie (pp. 561587). Armand Colin.

Winston-Smith, S., \& Hannigan, T. (2015). Swinging for the fences: How do top accelerators impact the trajectories of new ventures. Druid 15 Conference (pp. 1517).

Wise, S., \& Valliere, D. (2014). The impact on management experience on the performance of start-ups within accelerators. The Journal of Private Equity, 18(1), 9-19.

Wong, P., Ho, Y., \& Autio, E. (2005). Entrepreneurship, innovation and economic growth: Evidence from GEM data. Small Business Economics, 24(3), 335-350.

World Bank. (2019). Human capital project: First year annual progress report. World Bank Group.

Wronka, M. (2013). Analyzing the success of social enterprises-critical success factors perspective. Proceedings of the Management, Knowledge and Learning In ternartional Conference (pp. 593-605).

Wymer, S., \& Regan, E. (2005). Factors influencing e-commerce adoption and use by small and medium businesses. Electronic Markets, 15(4).

$\mathrm{Yu}, \mathrm{S}$. (2016). How do accelerators impact the performance of high-technology ventures? Management Science (forthcoming).

Zahra, S., Gedajlovic, E., Neubaum, D., \& Shulman, J. (2009). A typology of social entrepreneurs: Motives, search processes and ethical challenges. Journal of Business Venturing, 24(5), 519-532.

Zinger, J., LeBrasseur, R., \& Zanibbi, L. (2001). Factors influencing early stage performance in Canadian microenterprises. Journal of Developmental Entrepreneurship, 6(2), 129-150. 